paper by the late $\operatorname{Dr} P$ D Scott ${ }^{1}$ which was published at almost the same time as his untimely death.

Peter Scott was one of the founding fathers of the contemporary school of British forensic psychiatry and was possibly its most outstanding member. Certainly no one was better qualified to write on the assessment of dangerousness in criminals. His clinical experience was unique (he had personally examined well over 200 male murderers); he had appeared as an expert witness in innumerable murder trials, and had served until quite recently as a member of the British Parole Board. His paper is a distillate of his wide reading and his incomparable experience and is written, characteristically, in simple prose uncluttered by rhetoric or hyperbole.

To begin with he hazards a definition of dangerousnessnamely, "an unpredictable and untreatable tendency to inflict or risk serious, irreversible injury or destruction, or to induce others to do so." Next, he deals with prediction studies of dangerousness. He acknowledges their limitations and points out that in our parole system a prediction score, which is made for every male candidate, is useful, but not central in decisionmaking. He turns then to practical issues-the offence, past behaviour, personal data, and social circumstances. Facts should be made available to the psychiatrist on all four headings so that they can be scanned with a view to answering key questions: the most important are concerned with the "subject's capacity to feel sympathy with others, and his capacity to learn by experience." Also taken into account should be the prisoner's progress in custody and here Scott lays particular emphasis on the reports of members of staff who are in dayto-day contact with the prisoner patient. The availability of adequate after-care needs also to be considered carefully.

In his conclusions Scott remarks, ruefully perhaps, that in striving for accurate prediction of dangerousness, particularly in the long term, there is no magical process available. Nevertheless, by his example and by his work Scott has left behind him a platform of real substance on which others can build, cven if the ultimate goal of infallibility may always be beyond our reach.

1 Scott, P D, British Fournal of Psychiatry, 1977, 131, 127.

\section{Pain sensation in man}

Pain-and its relief-are central concepts in clinical medicine, yet research into pain mechanisms has long been dominated by physiologists. The breadth of current inquiry is apparent in the recent issue of British Medical Bulletin* devoted to somatic and visceral sensory mechanisms.

It has long been known that afferent peripheral nerves contain fast-conducting large myelinated fibres and slowerconducting small myelinated and non-myelinated fibres. ${ }^{1}$ Impulses concerned with pain are conveyed along myelinated A $\delta$ fibres and non-myelinated $\mathrm{C}$ fibres. ${ }^{2}$ This accounts for the numerous reports of first (fast) pain and second (delayed) pain induced in the skin by brief stimuli such as needle-prick or exposure to noxious heat. ${ }^{3-5}$ A $\delta$ fibres conduct at $10-25 \mathrm{~m} / \mathrm{sec}$ and $C$ fibres at $1 \mathrm{~m} / \mathrm{sec}$, and the interval between the two pain sensations may be as much as $1-1.5$ sec. $^{6}$ Moreover, the sensations induced by weak electrical stimulation of $\mathrm{A} \delta$ fibres are at first described as "tapping" or "throbbing," while

*Published by the Medical Department, The British Council; 65, Davies Street, London. stronger stimulation elicits a "pricking" sensation; C fibre activity requires still stronger stimulation, but the sensation is augmented and the enhanced pain is diffuse and often burning. These latter results, obtained in human experiments using percutaneous tungsten microelectrodes inserted into sensory nerves ${ }^{8}$ confirm many similar studies on animal responses to noxious stimulation. ${ }^{9}$ Pressure on sensory nerves selectively blocks A fibre responses, whereas weak concentrations of local anaesthetics block burning pain mediated by $\mathrm{C}$ fibres. ${ }^{10} \mathrm{Natural}$ non-noxious stimuli such as puffs of air, bending of hairs, and light touch do not produce C-fibre nerve impulses in man, whereas noxious heat, strong mechanical stimulation, and chemicals produce a definite and prolonged C-fibre discharge and burning sensation. ${ }^{11}$ The occurrence of polymodal nociceptors is well established. ${ }^{12}$ Pathological pain in man is probably always due to $\mathrm{C}$ fibre nociceptor activation. ${ }^{13}$

Interaction between large myelinated fibres and unmyelinated $\mathrm{C}$ fibres is well known and has been shown to occur in work in animals. ${ }^{14}$ The gate-control theory postulated an inhibitory presynaptic effect of large fibre nerve impulses on afferent $\mathrm{C}$ fibre activity, ${ }^{15}$ suggesting that this interaction occurred via cells of the substantia gelatinosa of the posterior horn of grey matter in the spinal cord. The gate-control theory is no longer acceptable in its original form, ${ }^{16}$ but has undoubtedly stimulated much clinical and experimental investigation of theoretical and practical importance. For instance, the pain of postherpetic neuralgia was attributed to selective destruction of large myelinated fibres in the affected nerves, ${ }^{17}$ but in many types of neuropathy there is no correlation between pain and the relative proportions of myelinated and nonmyelinated $C$ fibres. ${ }^{16}$ In patients with chronic pain brief intense stimulation of sensory nerves, which would normally activate all types of nerve fibre and be very painful, can produce remarkable relief of pain, sometimes for long periods and occasionally permanently. ${ }^{18}$

An interesting example of this effect has been the finding that brief intense transcutaneous electrical stimulation of myofascial and visceral trigger points can produce prolonged relief of chronic pain (for instance, in the lower back). ${ }^{19}$ The trigger points correspond very closely with acupuncture points, though the latter are chosen from an entirely different concept. The production of "hyperstimulation analgesia" may be due to excitation of segmental spinal cord neurones but more importantly of certain medial brain stem structures; the prolonged and sometimes permanent relief of pain may be due to suppression of "memory traces." 20 In many animals, including monkeys, electrical stimulation of periventricular or periaqueductal grey matter and of the medullary raphe nuclei has been shown to produce a profound, specific antinociceptive effect. ${ }^{21}$ Sensations other than pain are not suppressed. This stimulation-produced analgesia is exerted on the spinal cord via the descending dorsolateral funiculus. ${ }^{22}$

Narcotic analgesics such as morphine combine with opiate receptors in the same medial diencephalic grey matter and through the dorsal raphe nucleus activate the dorsolateral funiculus ${ }^{21}$ to inhibit nociceptive neurones in lamina $\mathrm{V}$ of the posterior horn grey matter. The dorsolateral funiculus is serotoninergic (it synthesises and releases serotonin or 5hydroxytryptamine) and depletion of its serotonin content by parachlorophenylalanine abolishes the analgesic action of morphine. ${ }^{21}$ Finally, regions of the brain which contain opiate receptors can synthesise pentapeptides called encephalins. These produce analgesia by combining with opiate receptors and are called endogenous ligands. ${ }^{23}$ The specific morphine antagonist naloxone not only prevents analgesia produced by 
morphine but also that produced by encephalins and electrical stimulation of the brain.

Developments in research into pain sensation have been so rapid recently that their potential cannot yet be estimated, but there seems every prospect that they will have clinical as well as theoretical importance.

1 Gasser, H S, Research Publications Association for Research in Nervous and Mental Disease, 1943, 23, 44

2 Zotterman, Y, Fournal of Physiology, London, 1939, 95, 1.

3 Lewis, T, and Pochin, E E, Clinical Science, 1937-38, 3, 67.

4 Sinclair, D C, and Stokes, B A R, Brain, 1964, 87, 609.

5 Price, D D, et al, Pain, 1977, 3, 57.

6 Lewis, T, Pain, New York, Macmillan, 1942.

${ }^{7}$ Hallin, R G, and Torebjörk, H E, Experimental Brain Research, 1973, 16, 309.

${ }^{8}$ Vallbo, A B, and Hagbarth, K E, Experimental Neurology, 1968, 21, 270.

- Iggo, A, British Medical Bulletin, 1977, 33, 97.

10 Torebjörk, H E, and Hallin, R G, Experimental Brain Research, 1973, 16, 321.

11 Torebjörk, H E, Acta Physiologica Scandinavica, 1974, 92, 374.

12 Zimmermann, M, in International Review of Physiology and Neurophysiology $I I$, vol 10, ed R Porter, p 179.

13 Mumford, J M, and Bowsher, D, Pain, 1976, 2, 223

14 Handwerker, H O, Iggo, A, and Zimmermann, M, Pain, 1975, 1, 147.

15 Melzack, R, and Wall, P D, Science, 1965, 150, 971.

16 Nathan, P W, Brain, 1976, 99, 123.

17 Noordenbos, W, Pain, Amsterdam, Elsevier, 1959

18 Melzack, R, Pain, 1975, 1, 357.

19 Melzack, R, et al, Pain, 1977, 3, 3

20 Nathan, P W, British Medical Bulletin, 1977, 33, 149.

${ }^{21}$ Mayer, D J, and Price, D D, Pain, 1976, 2, 379.

22 Basbaum, A I, et al, Pain, 1977, 3, 43.

${ }^{23}$ Hughes, J, and Kosterlitz, H W, British Medical Bulletin, 1977, 33, 157.

\section{Rotavirus gastroenteritis}

Infantile gastroenteritis used to be a summer illness, the socalled summer diarrhoea. When pathogens were detected they were usually bacteria, particularly various serotypes of Escherichia coli, but sometimes salmonellae, shigellae, or staphylococci were cultured. In the late 1940 s and ' 50 s enteropathogenic or toxigenic strains of $E$ coli caused several outbreaks of serious diarrhoea in Britain in infants and were often found in endemic infantile diarrhoea as well as in some adults with diarrhoea. ${ }^{12}$ Despite these advances probably half the cases of gastroenteritis in infants, presumably due to infection, could not be classified aetiologically, and in desperation clinicians often ended bedside discussions with the phrase "must be viral." Indeed, from time to time several, particularly enteroviruses and adenoviruses, ${ }^{3}$ are found in the stools of infants with diarrhoea, but even now we are still not sure whether their role is truly causal. In 1973 the scene changed, however, when a new viral contender-rotaviruswas detected by Bishop et $a l^{45}$ in the duodenal epithelium of six infants with acute nonbacterial gastroenteritis.

The virus has been given different names: human reoviruslike (HRVL), orbivirus, duovirus, and infantile gastroenteritis virus, but the designation which has probably found widest acceptance is rotavirus - the name being suggested by the wheel-like appearance of the virus on electron microscopy. Rotaviruses are $65 \mathrm{~nm}$ in diameter with a complete or spike (incomplete) outer surface; they are distinguishable from reoviruses in appearance and size. Rotaviruses are closely related to two other animal viral pathogens responsible for diarrhoea in calves and in infant mice. The principal illness produced by all three viruses is diarrhoea in the young of the appropriate species.

Methods for detecting the virus include electron microscopy using negatively stained virus particles ${ }^{6}{ }^{7}$; counter immunoelectrophoresis ${ }^{\mathbf{9}}$; estimation of serum complement fixing antibodies (using, for example, Nebraska calf diarrhoea virus as a substitute agent); a fluorescent antibody technique; and radioimmunoassay. Electron microscopy is useful and sensitive for rapid diagnosis. ${ }^{7}$ Very recently Yolken and colleagues ${ }^{10}$ have described an enzyme-linked immunoabsorbent assay which does not require complex technical equipment.

Since Bishop's demonstration of the virus particles in duodenal epithelium these have been identified in stools in infants with diarrhoea in Australia, Bangladesh, Britain, Canada, India, Japan, Norway, Rhodesia, Singapore, South Africa, and the United States. ${ }^{11-13}$ Most reports agree on certain common factors. Diarrhoea is the prime clinical manifestation. Outbreaks occur in families or institutions; children aged 6 months to 3 years are particularly susceptible, but older children and adults may excrete the virus. Diarrhoea is not always present, and the incidence of disease is highest in the colder months of the year.

Why should we accept with alacrity an aetiological role for rotavirus when we have not accepted, or at best accepted only with reluctance, such a role for adenoviruses and enteroviruses? The scale of the evidence and its world-wide extent present a convincing and consistent picture of rotavirus enteritis, which contrasts with the sporadic nature of the evidence for most other viruses. In a very few years rotavirus diarrhoea has become as well established as that due to toxigenic strains of $E$ coli. Compelling as the epidemiological evidence is, however, some questions remain to be answered. Do these viruses alone cause diarrhoea, or do they require the presence of some other agent-bacterial or viral-for the full expression of their pathogenicity? What part, if any, do they play in chronic intestinal disease, such as Crohn's disease or ulcerative colitis ? $^{14}$ Some of these unresolved questions have been nicely posed by a detailed study of stool pathogens-viral and bacterial-in infants with diarrhoea in Glasgow. ${ }^{15}$ The Scottish workers found a number of different viruses (including rotaviruses) and bacterial pathogens often occurring within a few days in different stool samples from the same infants with diarrhoea. When several different pathogens are present which one causes the illness?

Faced with a young infant with acute gastroenteritis, age and time of year apart, can the doctor detect any clues which might lead to a correct clinical diagnosis of rotavirus diarrhoea? There are very few certainties, merely a few pointers. Infants with rotavirus diarrhoea may have prolonged diarrhoea with large volumes of stools and may on average require intravenous replacement more often than patients with diarrhoea due to $E$ coli. Nevertheless, these debatable distinctions may not be helpful in individual cases. In viral enteritis leucocytes may not be present in the stools. In many infants who present with gastroenteritis there is often a history of a preceding respiratory illness and sometimes there are signs of infection in the respiratory system. Similarly, children with respiratory infections sometimes have diarrhoea; in both groups antibiotics may be blamed for gastrointestinal symptoms. May we also add another variable-might the rotavirus infections responsible for infantile gastroenteritis also cause the respiratory symptoms so often found in these infants?

\footnotetext{
${ }^{1}$ Gross, R J, Scotland, S M, and Row, B, Lancet, 1976, 1, 629.

${ }^{2}$ Rowe, B, Taylor, J, and Bettelheim, K A, Lancet, 1970, 1, 1.

${ }^{3}$ Ramos-Alvarez, M, and Clarte, J, American fournal of Diseases of Children, $1964,107,218$.

- Bishop, R F, et al, New England fournal of Medicine, 1973, 289, 1096.

${ }_{5}$ Bishop, R F, et al, Lancet, 1973, $2,1281$.
}

6 Bryden, A S, et al, Lancet, 1975, 2, 241. 